US Army Corps

of Engineers ${ }_{\circledast}$

Engineer Research and

Development Center

ERDC Technology Transfer and Infusion/Knowledge Management

\title{
Google Search Appliance End of Life and Replacement Recommendations
}

Byron M. Garton, Jonathan S. Broderick, June 2019 and Brandon K. Randle 
The U.S. Army Engineer Research and Development Center (ERDC) solves the nation's toughest engineering and environmental challenges. ERDC develops innovative solutions in civil and military engineering, geospatial sciences, water resources, and environmental sciences for the Army, the Department of Defense, civilian agencies, and our nation's public good. Find out more at www.erdc.usace.army.mil.

To search for other technical reports published by ERDC, visit the ERDC online library at http://acwc.sdp.sirsi.net/client/default. 


\section{Google Search Appliance End of Life and Replacement Recommendations}

Byron M. Garton, Jonathan S. Broderick, and Brandon K. Randle

Information Technology Laboratory

U.S. Army Engineer Research and Development Center

3909 Halls Ferry Road

Vicksburg, MS 39180

Final Report

Approved for public release; distribution is unlimited.

Prepared for Headquarters, U.S. Army Corps of Engineers

Washington, DC 20314-1000 


\section{Abstract}

The Engineering Research and Development Center (ERDC) Knowledge Management relies on a search technology provided by Google. Known as the Google Search Appliance (GSA), it indexes and searches ERDC's accumulation of knowledge stored on various web connected systems. The GSA provides a familiar and simple to use interface to facilitate quick location and retrieval of ERDC knowledge stored on these systems that are located on ERDC's internal and extra-net websites. In 2016, Google announced the discontinuation of the GSA product at the end of March 2019.

This document details the investigation into potential GSA replacement options and the recommended actions to be taken to minimize the impact of the March 2019 sunset. Emphasis is placed on equivalent or enhanced feature sets, ease of installation and migration, and the costs associated with installation, migration, and maintenance.

DISCLAIMER: The contents of this report are not to be used for advertising, publication, or promotional purposes. Citation of trade names does not constitute an official endorsement or approval of the use of such commercial products. All product names and trademarks cited are the property of their respective owners. The findings of this report are not to be construed as an official Department of the Army position unless so designated by other authorized documents. 


\section{Contents}

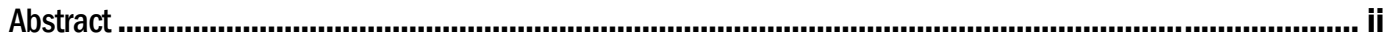

Figures and Tables...........................................................................................................................iv

Preface...................................................................................................................................................

Acronyms and Abbreviations............................................................................................................... vi

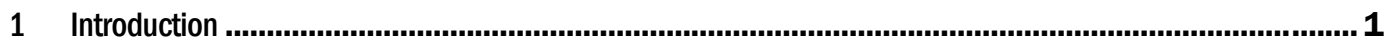

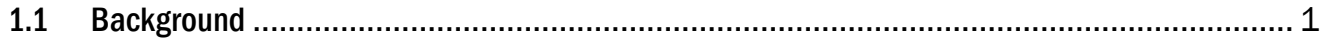

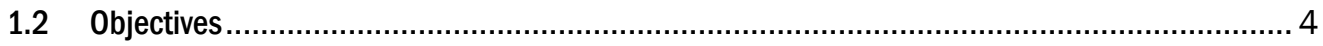

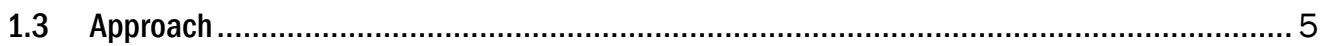

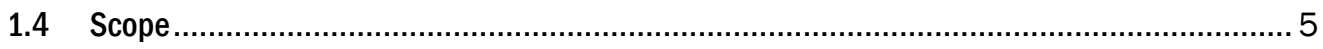

2 Replacement Options............................................................................................................... 6

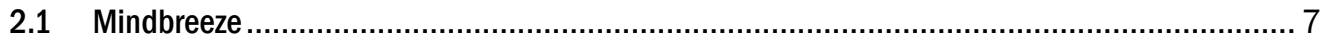

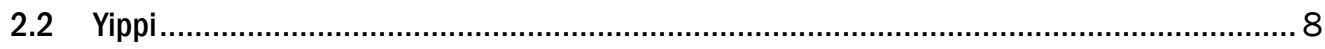

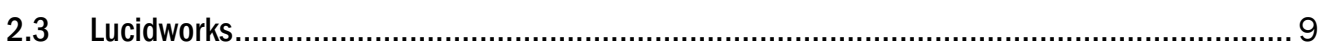

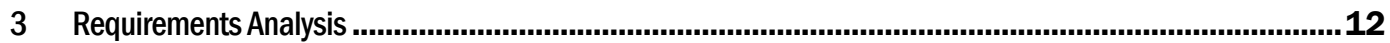

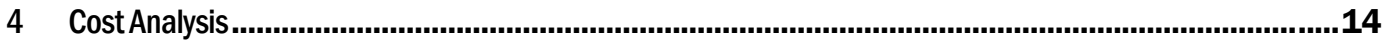

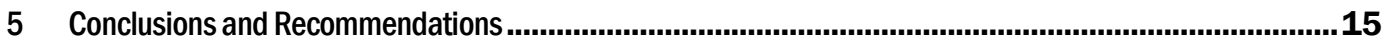

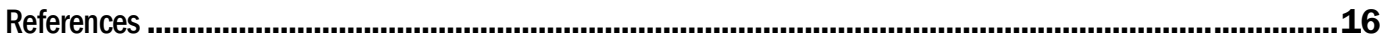

\section{Report Documentation Page}




\section{Figures and Tables}

\section{Figures}

Figure 1. The Discover ERDC landing page search box performs searches on the GSA. .................................... 2

Figure 2. Accessing the GSA directly is also a method of performing searches. ............................................... 3

Figure 3. Search results are presented in the familiar Google search style. ...................................................... 4

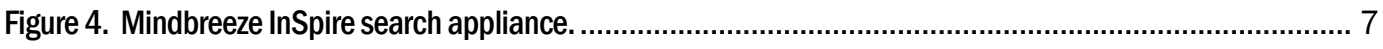

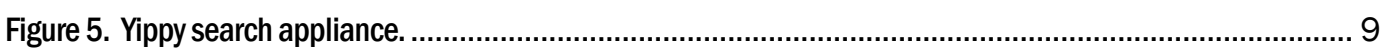

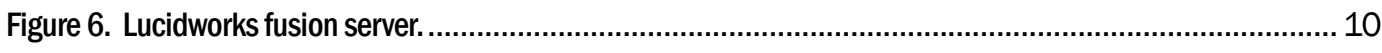

\section{Tables}

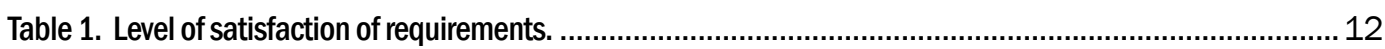

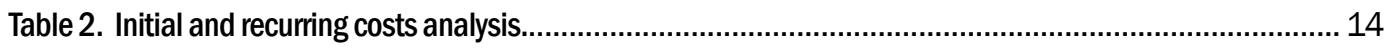




\section{Preface}

This research was conducted for the Engineering Research and

Development Center (ERDC) Office of Research and Technology Transfer (ORTT) utilizing 219 CDR funding for "ERDC Technology Transfer and Infusion/Knowledge Management.” The technical monitor was Ms. Antisa Webb.

The work was performed by the Scientific Software Branch (SSB) of the Computational Science and Engineering Division (CSED), U.S. Army Engineer Research and Development Center - Information Technology Laboratory (ERDC-ITL). At the time of publication, Mr. Timothy Dunaway was Chief, CEERD-SSB; and Dr. Jerrell R. Ballard was Chief, CEERD-IES. The Technical Director for Engineered Resilient Systems was Dr. Robert M. Wallace. The Deputy Director of ERDC-ITL was Ms. Patti S. Duett, and the Director was Dr. David A. Horner.

COL Ivan P. Beckman was the Commander of ERDC, and Dr. David W. Pittman was the Director. 


\section{Acronyms and Abbreviations}

$\begin{array}{ll}\text { Term } & \text { Definition } \\ \text { API } & \text { Application Programming Interface } \\ \text { CSED } & \text { Computational Science and Engineering Division } \\ \text { DoD } & \text { Department of Defense } \\ \text { DISA } & \text { Defense Information Systems Agency } \\ \text { eMASS } & \text { Enterprise Mission Assurance Support Service } \\ \text { ERDC } & \text { Engineer Research and Development Center } \\ \text { FTE } & \text { Full Time Equivalent } \\ \text { HPC-MP } & \text { High Performance Computing Modernization Program } \\ \text { ITL } & \text { Information Technology Laboratory } \\ \text { ORTT } & \text { Office of Research and Technology Transfer } \\ \text { PKI } & \text { Public Key Infrastructure } \\ \text { RDE } & \text { Research and Development Environment } \\ \text { RMF } & \text { Risk Management Framework } \\ \text { SAML } & \text { Security Assertion Markup Language } \\ \text { SSO } & \text { Single Sign On } \\ \text { STIG } & \text { Security Technical Implementation Guide } \\ \text { YSA } & \text { Yippy Search Appliance }\end{array}$




\section{Introduction}

\subsection{Background}

The Engineer Research and Development Center (ERDC) has embarked on several knowledge management initiatives over the years in an effort to make the accumulation of knowledge easier to catalog, locate, and share. Knowledge cataloging and locating initiatives have been focused on a combination of technologies including enterprise search. Historically, the industry leader in enterprise search has been Google. In 2002, Google introduced a rack-mounted computing device containing its prized search technology to the enterprise search market. Deemed the Google Search Appliance (GSA), the intention of this device was to put the power of Google's indexing and search technology in the hands of enterprises around the world.

When purchasing a GSA from Google, a physical rack-mounted server is delivered to customers to install within their enterprise network. Sales are conducted through licensing which typically includes a maximum number of stored indexes and begins with a two year contract for maintenance, technical support, and software updates. Three year contracts are also available. Out of the box, the search appliance contains Google's ubiquitous user facing search interface and highly acclaimed indexing software. The search interface is customizable to better match the enterprise's look and feel by allowing the changing of colors, logos, etc.

Since its release, the GSA has been adopted by many private and public industries, including ERDC. The enticement of the GSA to ERDC was the ability to index and search organizational data such as website content, documents, photos, videos, etc. within ERDC's internal Research and Development Environment (RDE) network. The GSA's ability to perform these functions using Google's world renowned web crawling and search algorithms and its simple integration into existing knowledge management applications are its most appealing attributes.

The GSA has been indexing and serving search results to ERDC intranet users since 2010 when it was installed and integrated into the RDE network. Thirty servers on the ERDC RDE network, including intranet, extranet, and knowledge management websites (e.g., internal and external 
wikis) are currently indexed by the GSA. Users access the GSA by typing a search string into the search box at the top of the Discover ERDC landing page (htps://discover.erdc.dren.mil), or by directly accessing the search appliance home page (https://search.erdc.dren.mil). Figures 1-3 show these methods of accessing the GSA from a knowledge consumer's prospective.

The GSA has served ERDC knowledge management efforts well since inception. Unfortunately, Google announced the discontinuation of the GSA in February, 2016. End of life is scheduled for March, 2019 (Google Search Appliance End of Life n.d.), and no new licenses have been issued since 2016. Google's new approach to enterprise search leans heavily on cloud computing, and they have advised current GSA customers to adopt the new cloud technology. Indexing search results in a cloud environment introduces a host of security and regulatory issues outlined by numerous Security Technical Implementation Guides (STIGs) written and disseminated to Department of Defense (DoD) entities by the Defense Information Systems Agency (DISA).

Figure 1. The Discover ERDC landing page search box performs searches on the GSA.

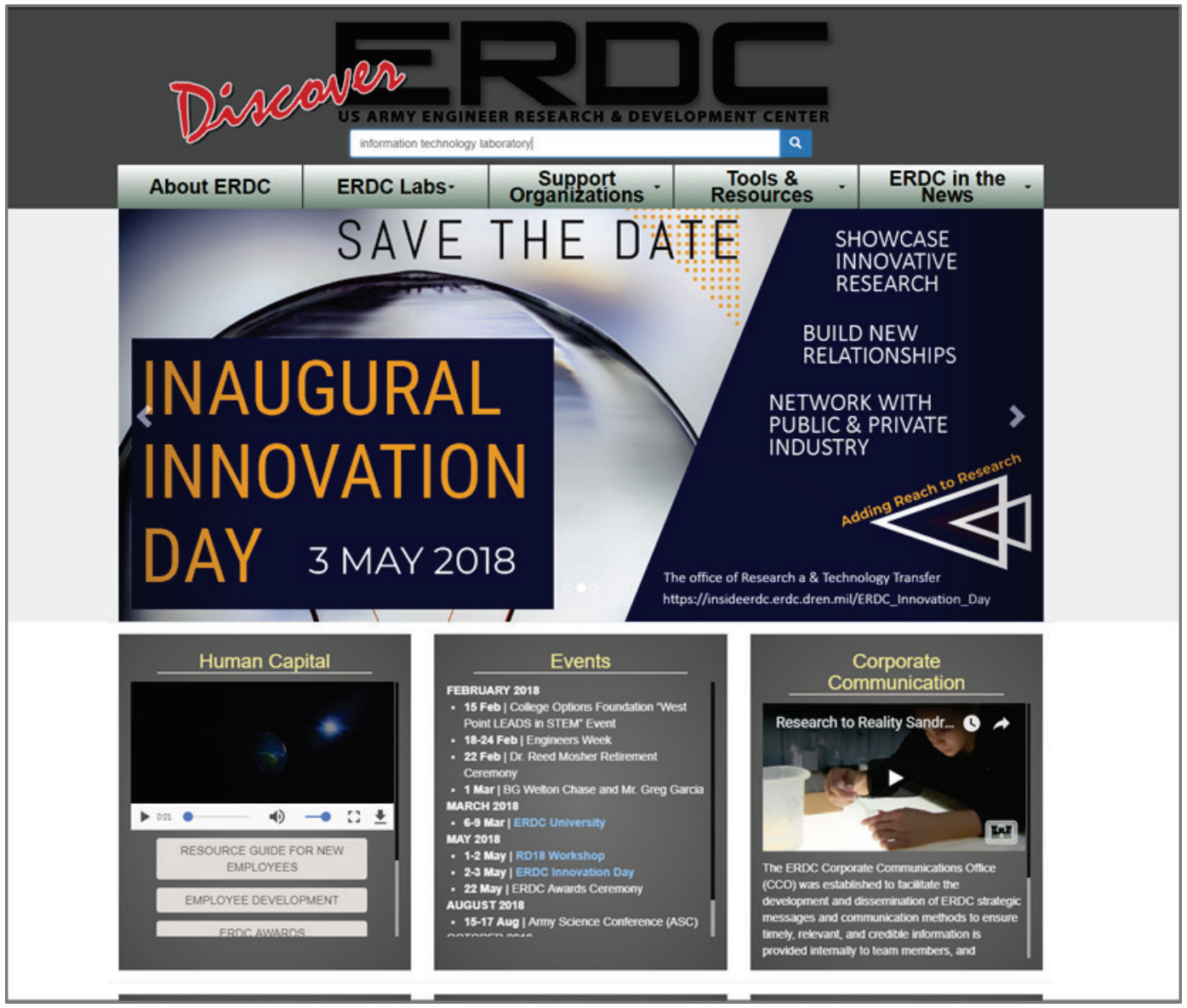


Figure 2. Accessing the GSA directly is also a method of performing searches.

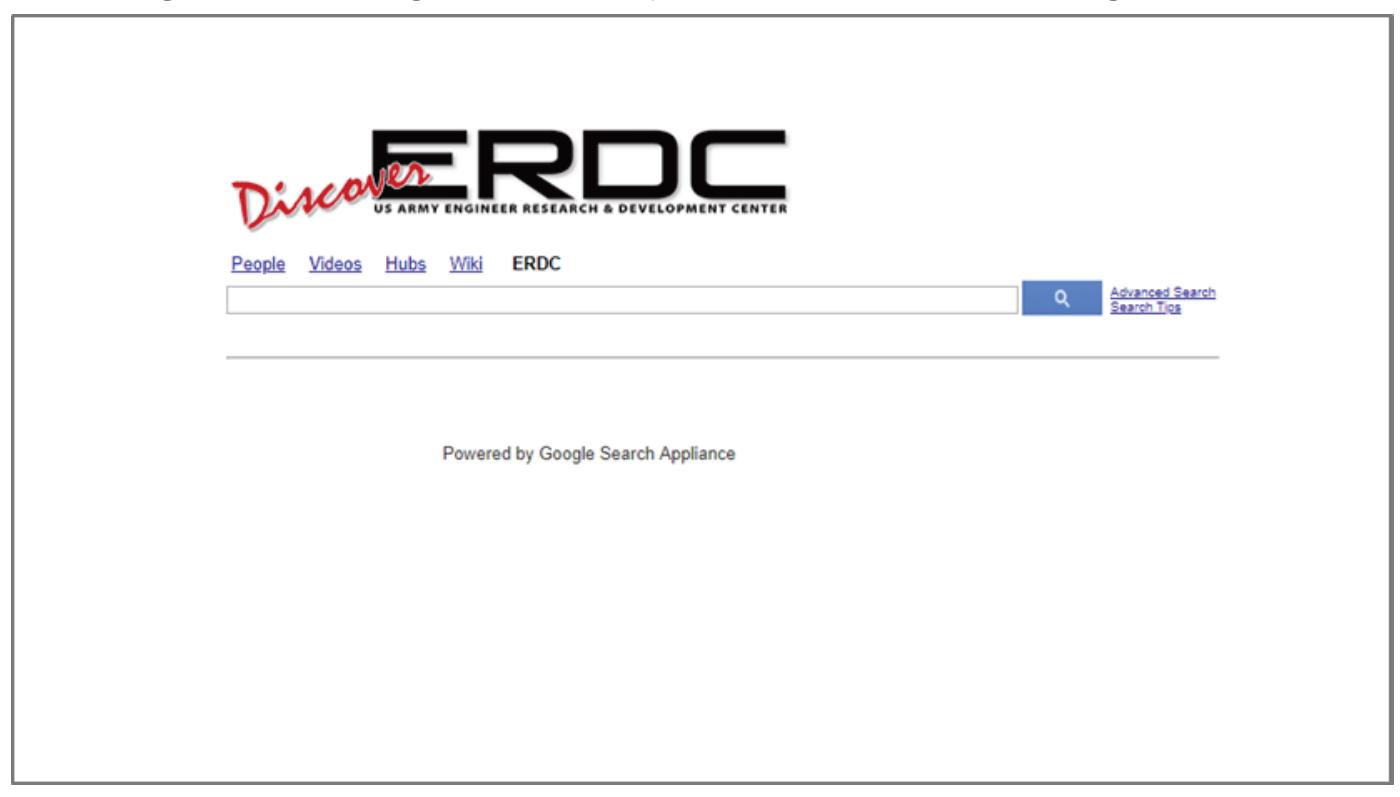


Figure 3. Search results are presented in the familiar Google search style.

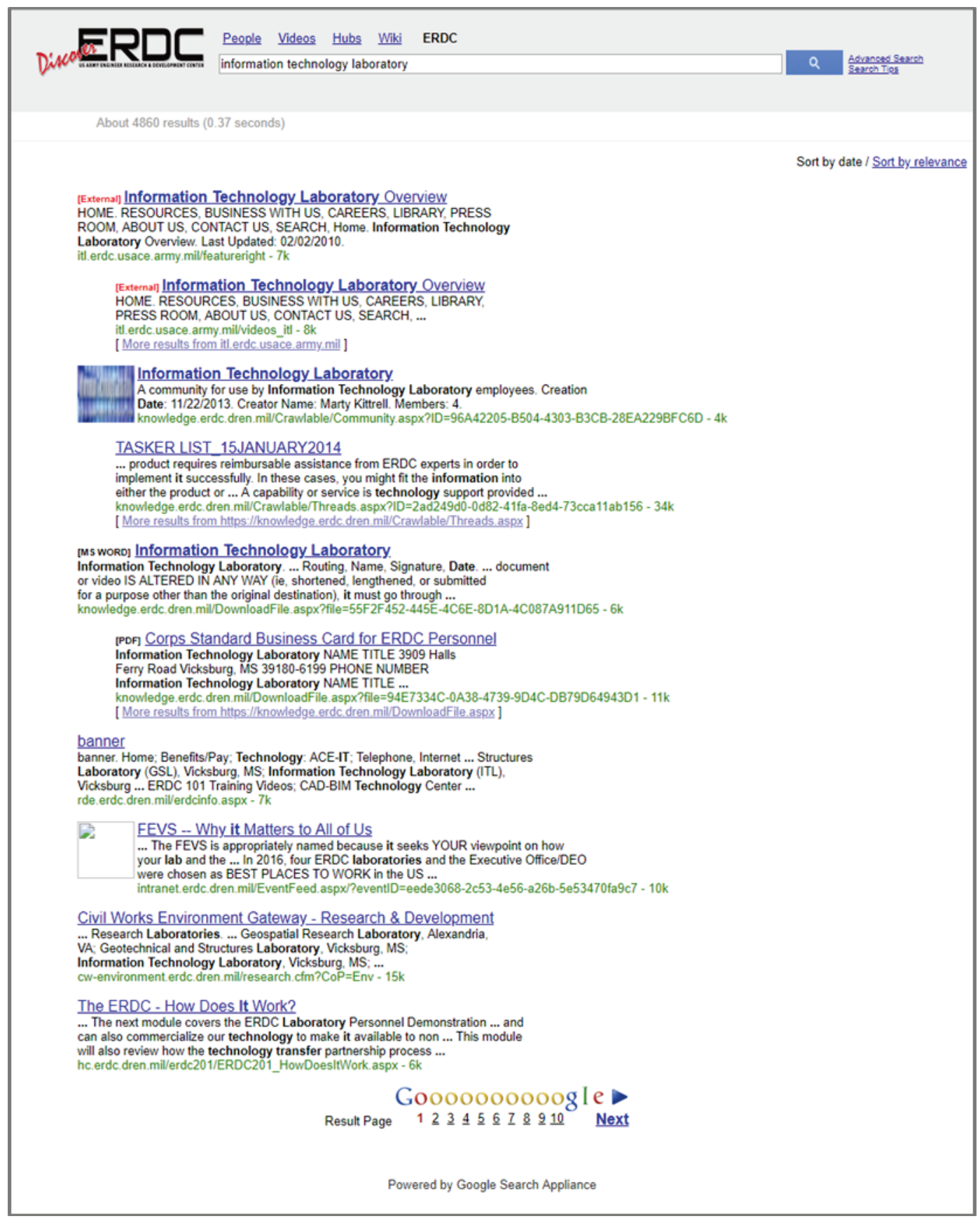

\subsection{Objectives}

Several private industry companies have recognized the security and regulatory issues that governments and their agencies are facing when preparing to replace their GSAs and are offering competing products to solve those issues. This document explores these products with emphasis placed on equivalent or enhanced feature sets, ease of installation and migration, and costs associated with migration and maintenance. 


\subsection{Approach}

Research into GSA replacement search technologies was performed online using standard web search methods. Upon location of a potential candidate, information was gathered from the candidate's website, and in some instances communication was initiated to their technical support to further clarify the information.

Following the information gathering phase, each potential candidate's information was analyzed to determine if the technology met specified requirements in the areas of functionality and cost. Each technology was given a satisfaction rating based on the how completely the specified requirements were satisfied. A recommended course of action was selected following the requirements and costs analyses.

\subsection{Scope}

The purpose of this study was to determine the best course of action to take to replace the GSA prior to its end of life. Online research revealed a plethora of search technologies exist on the private marked, but the research was focused on technologies that most closely replicate the existing functionality of the GSA. From a larger list of potential candidate technologies, a condensed list of three technologies was selected that could most likely meet all the specified requirements. 


\section{Replacement Options}

Now that the GSA is nearing end-of-life, several companies are hoping to provide solutions to entities where security and regulatory concerns are prominent and cloud search technologies are not viable. For example, Google's cloud search service would require the ERDC-RDE to allow access to internal content from the Internet which is a violation of security protocols.

Candidate systems must meet certain baseline requirements in the areas of functionality, ease of installation, long term viability, initial and recurring costs, and maintenance. Baseline functionality of a GSA replacement system must account for the following capabilities:

1. Hardware must meet or exceed current GSA hardware capabilities.

2. Installation of the replacement system must be easily achieved by existing ERDC personnel or contracted labor from the product vendor.

3. The ability to index internal and extranet content on ERDC servers from within the RDE network.

4. Support existing RDE authentication methods for knowledge consumers and provide a method for authentication while indexing content on servers that require authentication prior to access.

5. Provide a customizable user interface for allowing searches to be made on the indexed data and output results in an easy to use and understandable format.

6. Not limit the size or number of indexes that can be made or provide simple methods to increase the number of allowable indexes in order to scale and satisfy long term viability requirements.

7. Software must allow customizability in order to meet unforeseen future requirements through the use of open source software or timely customization from the product vendor.

8. The ability to acquire security certifications for installation on $\mathrm{RDE}$ network prior to GSA end-of-life.

9. Provide responsive and timely technical support in case problems arise.

Online research was conducted to identify companies and products which could potentially meet these baseline requirements. Each company identified was contacted and requested to provide information related to the baseline requirements. The following sections detail the collected information for each company. 


\subsection{Mindbreeze}

Mindbreeze $\mathrm{GmbH}$ is an enterprise search technology company based in Linz, Austria. Founded in 2005, Mindbreeze has positioned to become a global leader in knowledge management and machine learning and is positioned in the Leaders Quadrant of the Gartner's 2018 Magic Quadrant for Insight Engines (Ulrike 2018). In 2018, KMWorld listed Mindbreeze in its list of 100 Companies that Matter in Knowledge Management (Ulrike 2018). Mindbreeze has earned this honor nine consecutive times.

Figure 4. Mindbreeze InSpire search appliance.

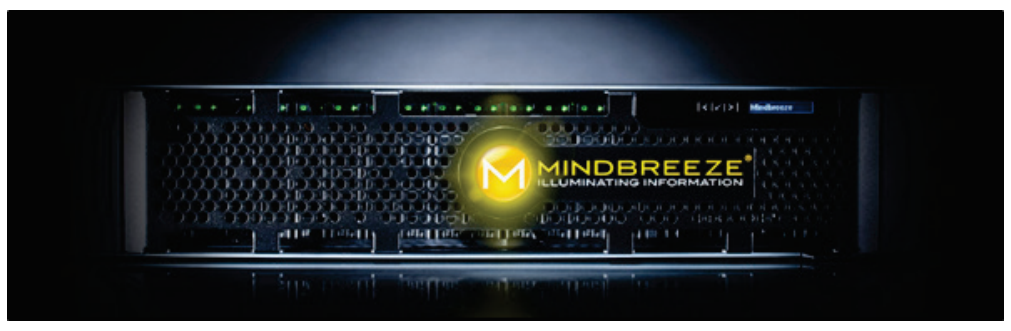

The Mindbreeze InSpire search appliance is a server based search technology that is very similar to the GSA. It is a physical device that is rack-mounted and connected to the network, and installation of the appliance can be performed by ERDC personnel or contracted labor from the product vendor.

InSpire been developed and marketed as a direct replacement for the GSA, and much effort has been put into making migration from the GSA to InSpire as simple as possible. All of the current GSA functionality has been replicated in the software that runs on InSpire, and additional connectors and authentication protocols beyond those provided by GSA are included. Mindbreeze also provides a GSA migration tool which copies the configuration settings from a GSA which reduces the amount of setup and configuration work. Search results are displayed in a format very reminiscent of Google search results and the results template is customizable by the customer to better integrate into their environment.

InSpire is coded to work with authentication methods currently deployed on the ERDC-RDE network including Public Key Infrastructure (PKI) and Single Sign On (SSO) utilizing Security Assertion Markup Language (SAML). These authentication methods can be used to access the search functionality or during indexing of data stores that are access restricted. 
Over 450 types of data connectors are included in the software which allows the device to connect to nearly every type of data source.

The InSpire search appliance software runs from a subscription model very similar to the GSA model. Different levels of subscription service are defined based on the number of indexes the customer wishes to store, with the price increasing as the number of indexes increases. Packages start at 500,000 indexes and go up to 10,000,000+ indexes, although above 10,000,000 indexes, additional hardware must be purchased. Appliances can be connected in a daisy-chain configuration, increase processing and indexing capabilities.

Basic technical support comes standard with the purchase of an InSpire appliance. Additional technical support can be purchased, including an option for 24×7 365 remote access support option for instant support over the Internet. Mindbreeze also provides on-site installation and training courses as additional support options. These options come with additional costs.

\subsection{Yippi}

Yippy Inc. is an enterprise search technology company based in Marco Island, FL. Founded in 2009, Yippy has evolved from its educational roots into a leading provider of search and eDiscovery technologies for all types of consumers of data. Yippy's search technology was born out of Carnegie Mellon, and was purchased by the company in 2010. Yippy includes search software known as Velocity by Vivisimo which was acquired by IBM in 2012 and renamed IBM Watson Explorer ${ }^{\circledR}$ (Granville n.d.).

Yippy has developed a server based search appliance called Yippy Search Appliance (YSA) very similar to the Mindbreeze InSpire and GSA. It is also a physical device that is rack-mounted and connected to the network. Installation of the appliance can be performed by ERDC personnel or contracted labor from the product vendor. 
Figure 5. Yippy search appliance.

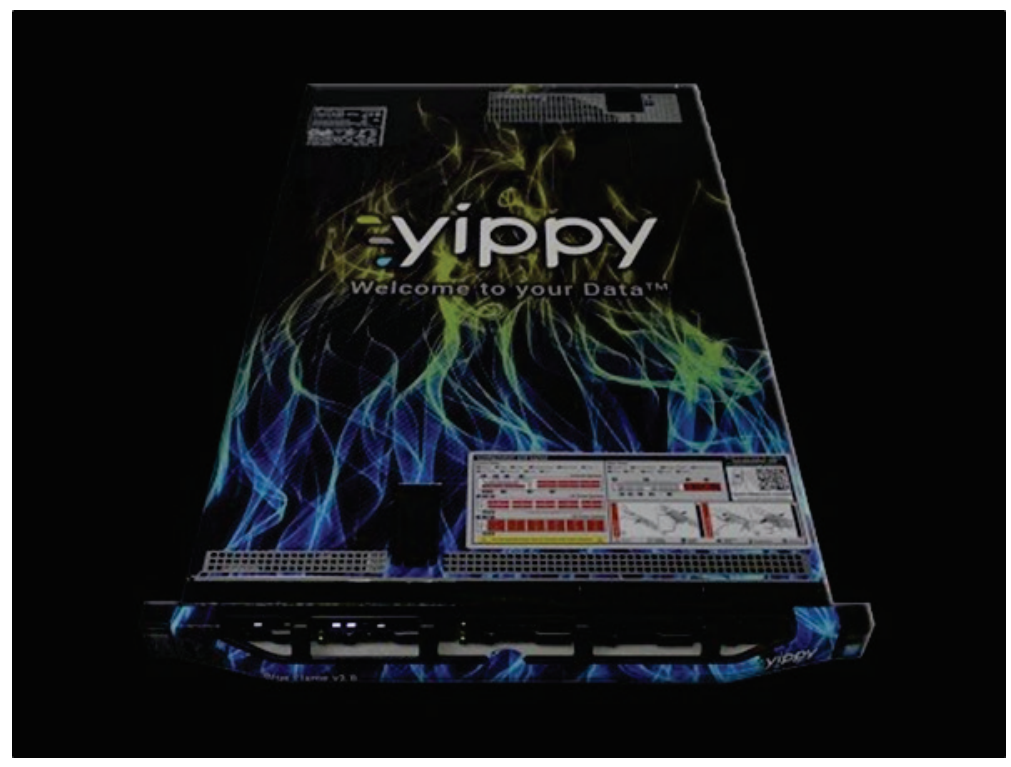

As a relative new comer to the market, Yippy has also developed and marketed the YSA as a direct GSA replacement. The YSA has all the same features as the GSA and InSpire, and runs on a similar subscription model. The required authentication methods are integrated and the search interface is customizable. A multitude of data connectors are included to connect to all required data sources.

The main differentiation between the GSA, InSpire, and YSA is the fact that YSA utilizes IBM's Watson artificial intelligence to perform natural language searches. With IBM as Yippy's third largest shareholder, IBM's vast amount of continuing research into artificial intelligence provides the ability to quickly combine data with natural language search.

Yippy also provides technical support in a very similar manner as Mindbreeze, with basic support supplied with appliance purchase and additional support including on-site installation and training at additional costs.

\subsection{Lucidworks}

Lucidworks is an enterprise search technology company based in San Francisco, CA. Originally founded in 2007 as Lucid Imagination, Lucidworks offers an application development platform including a machine learning and signal processing engine built on top of the open source Apache Solr search platform that promises to allow corporations to 
"translate massive pools of data into actionable insights faster than ever" (Carney 2014) (Figure 6).

Figure 6. Lucidworks fusion server.

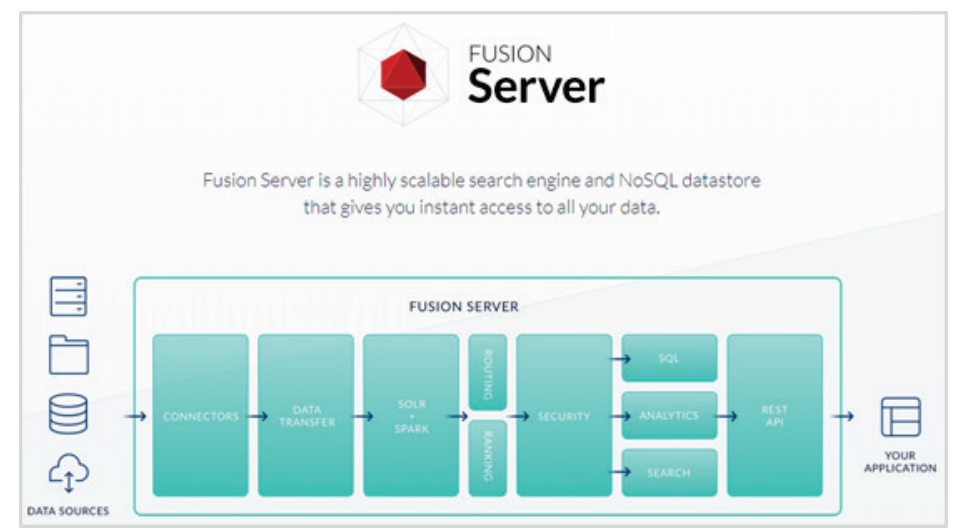

Lucidworks has taken a different approach to tackling enterprise search and knowledge management. Rather than develop an appliance based search solution, they have leveraged open source software from Apache and built enterprise level capabilities on top it. Lucidworks Fusion Server is the company's enterprise search software that performs data indexing and provides an Application Programming Interface (API) for access to those indexes. Open source software typically does not come with a price or subscription, and this is the case with Lucidworks Fusion Server. The software is freely downloadable from the company's website.

Since the solution is software only, additional servers must be provided inhouse to run the application. Installation and configuration of the software on in-house hardware will also require in-house labor, as Lucidworks does not provide any on-site installation services that were locatable. This is expected since open source applications typically do not come with warranties or support.

In addition to hardware requirements, Lucidworks Fusion Server requires custom programming to function as required. Once the application is installed and configured, it can begin indexing data sources within RDE. Those indexes are stored within the application's database. Access to those indexes within the database is gained through the application's API. The API simply provides an entry point into the data, not a fully functioning search page for end users. A custom search page will have to be developed in-house to connect to the API entry points, retrieve the indexed items from the database, and present them to the user performing the search. 
Lucidworks Fusion Server is coded to support PKI and SSO authentication protocols. Since it is an open source application, it can be highly customized to work with any protocol RDE may support in the future. There should be no issues with accessing authentication protected content during data indexing. A wide array of data connectors are also preloaded to allow connections to numerous types of data sources. The number of indexes that can be stored is essentially unlimited. The only limitation is the amount of physical storage space on the host server or its network attached storage. 


\section{Requirements Analysis}

Each of the three potential enterprise search solutions listed previously were analyzed independently to identify their level of satisfaction of ERDC's knowledge management requirements. The table below illustrates the level of satisfaction of requirements for each solution.

Table 1. Level of satisfaction of requirements.

\begin{tabular}{|l|c|c|c|}
\hline Requirement & $\begin{array}{c}\text { Mindbreeze } \\
\text { InSpire }\end{array}$ & $\begin{array}{c}\text { Yippy Search } \\
\text { Appliance }\end{array}$ & $\begin{array}{c}\text { Lucidworks } \\
\text { Fusion Server }\end{array}$ \\
\hline $\begin{array}{l}\text { Meets or exceeds current GSA } \\
\text { functionality }\end{array}$ & & & \\
\hline $\begin{array}{l}\text { Installation achieved by ERDC } \\
\text { personnel or vendor }\end{array}$ & & & \\
\hline $\begin{array}{l}\text { Indexes internal and extranet content } \\
\text { on RDE network }\end{array}$ & & & \\
\hline $\begin{array}{l}\text { Supports with RDE authentication } \\
\text { protocols }\end{array}$ & & & \\
\hline $\begin{array}{l}\text { Customizable end user search } \\
\text { interface }\end{array}$ & & & \\
\hline $\begin{array}{l}\text { Allowable number of indexes is } \\
\text { scalable }\end{array}$ & & & \\
\hline $\begin{array}{l}\text { Customizable to meet future } \\
\text { requirements }\end{array}$ & & & \\
\hline $\begin{array}{l}\text { Responsive and timely technical } \\
\text { support available }\end{array}$ & & & \\
\hline $\begin{array}{l}\text { Security certification achievable prior } \\
\text { to GSA end of life }\end{array}$ & & & \\
\hline
\end{tabular}

$=$ High Satisfaction, $O=$ Moderate Satisfaction, $O=$ Low Satisfaction

All three solutions meet almost all of the defined requirements. Since Lucidworks Fusion Server does not provide a search page for end users by default, it only partially satisfies the requirement of meeting or exceeding 
current GSA functionality. Additionally, Lucidworks Fusion Server is open source software and does not satisfy the requirement of providing responsive and timely technical support.

The major point of interest during the requirements analysis is that a solution must be able to acquire the necessary security certifications to operate on the ERDC-RDE network prior to the GSA end of life in March 2019. This requirement is essential to the successful replacement of the GSA and the continuity of enterprise knowledge management across ERDC. The RDE operates under the umbrella of U.S. Army network security requirements. The current method of determining net worthiness of an information operating on an Army network is successful completion of the Risk Management Framework (RMF) process. This process is facilitated by the Enterprise Mission Assurance Support Service (eMASS) which is administered by DISA. The eMASS manages and facilitates the acquisition of an RMF certification of an information system by identifying various security controls and requires those controls to be fully satisfied by the information system owner prior to certification. Typically, this process to take up to twelve months to complete.

None of the potential solutions currently have an RMF certification, and since end of life for the GSA is less than twelve months away, they will not be able to meet the RMF requirement. Luckily, the RMF process for the Mindbreeze InSpire appliance was begun in February of 2018 by the High Performance Computing Center Modernization Program (HPC-MP) as part of an independent knowledge management initiative within that program. When received, that certification can be used to certify a Mindbreeze appliance on the RDE network, therefore, satisfying the RMF requirement. While it may be possible that the Yippy Search Appliance and Lucidworks Fusion Server are currently being RMF certified under other programs, no evidence supporting that could be found. 


\section{Cost Analysis}

It is essential when determining an enterprise search solution to analyze the costs associate with successful implementation. Costs come in the form of acquisition, subscription, installation, configuration, certification, training, support, and maintenance. The table below enumerates these costs for each of the three potential search solutions.

Table 2. Initial and recurring costs analysis.

\begin{tabular}{|c|c|c|c|}
\hline Cost & Mindbreeze InSpire & Yippy SearchAppliance & Lucidworks Fusion Server \\
\hline Acquisition & $\$ 68 \mathrm{~K}$ & $\$ 35 \mathrm{~K}$ & $\$ 0$ \\
\hline Subscription & $\begin{array}{l}\text { Included in acquisition } \\
\text { (3 years) }\end{array}$ & $\begin{array}{l}\text { \$35K } \\
\text { (annually after year 1) }\end{array}$ & $\$ 0$ \\
\hline Installation & $* \$ 4 \mathrm{~K}$ & $\$ 5 K$ & $* \$ 4 \mathrm{~K}$ \\
\hline Configuration & Included in acquisition & $\$ 5 K$ & $* \$ 50 \mathrm{~K}$ \\
\hline Certification & $* \$ 200 K$ & $* \$ 300 \mathrm{~K}$ & *\$300K \\
\hline Training & $\$ 4 \mathrm{~K}$ & $\$ 5 \mathrm{~K}$ & Not available \\
\hline Support & Included in acquisition & Included in acquisition & Not available \\
\hline Maintenance & Included in acquisition & Included in acquisition & $\begin{array}{l}* \$ 200 K \\
\text { (annual) }\end{array}$ \\
\hline Initial Total Cost & $\$ 276 K$ & $\$ 350 K$ & $\$ 554 K$ \\
\hline Recurring Costs & $\begin{array}{l}\text { \$68K subscription } \\
\text { renewal every } 3 \text { years }\end{array}$ & $\begin{array}{l}\text { \$35K subscription } \\
\text { renewal annually }\end{array}$ & $\begin{array}{l}* \$ 200 K \text { annual } \\
\text { maintenance }\end{array}$ \\
\hline
\end{tabular}

* Estimated in-house labor is one Full Time Equivalent (FTE) at DB4 level.

Despite an initial and subscription cost of zero dollars, Lucidworks Fusion Server has very high initial and recurring costs due to the extensive amount of development, customization, and maintenance that is required to make and keep it functional. Because the RMF process for Mindbreeze InSpire has already begun within the HPC-MP, the certification costs for the system are significantly lower than the other solutions.

Initial, subscription, and recurring costs for the Mindbreeze InSpire and Yippy Search Appliance are very similar. They are competing products, so this is expected. The main difference between the two is installation for the Mindbreeze InSpire appliance is not provided by the vendor and must be conducted with in-house labor. Yippy provides on-site installation by a vendor provided technician at a slightly higher cost. Both vendors provide training for appliance administrators at a very competitive additional cost. 


\section{Conclusions and Recommendations}

There are many market players in the enterprise search game and many different approaches to solving the same problem. Multiple companies and products other than the three enumerated in this report were researched and considered. After a requirements analysis of all the various search solutions, these three were chosen because they most closely aligned with ERDC knowledge management requirements.

Each of the three selected potential search solutions meet nearly all the requirements, but the security certification acquisition requirement was a key factor in selecting a recommendation. Mindbreeze InSpire has a clear advantage because an RMF process has already been started in an effort to have it certified on the HPC network, and that certification can be leveraged to certify the net worthiness of the appliance on the RDE network. Additionally, there is already some Mindbreeze expertise within HPC that RDE can leverage to reduce the configuration effort. Recurring costs associated with Mindbreeze are slightly lower than the other solutions which is a great benefit to ERDC.

It is recommended that ERDC purchase and install two Mindbreeze InSpire search appliances to successfully replace the GSA prior to its end of life. Two appliances should be purchased because one will serve as a hot backup to fail over to in case one encounters issues that take it offline. The cost enumerated in the previous section reflects the cost of the two appliances. Collaborating with Mindbreeze technical support during requirements gathering and configuration is also recommended to help facilitate the successful implementation of the system on the RDE network.

ERDC knowledge management is essential to maintaining successful execution of programs, and this recommendation should be carried out as soon as possible by the ERDC Office of Research and Technology. Carrying out this recommendation and collaborating with the ERDC Information Technology Laboratory to ensure successful implementation will ensure the continuity of search functionality across the entire range of ERDC's knowledge management information systems and allow ERDC to continue to successfully deliver its mission. 


\section{References}

Carney, Michael. 2014. LucidWorks debuts new Fusion platform, offers modularized, personalized search for the enterprise. Retrieved from https://pando.com/2014/09/18/lucidworks-debuts-new-fusion-platform-offers-modularizedpersonalized-search-for-the-enterprise/

Google Search Appliance End of Life. n.d. (Accessed on 2 July 2019). https://support.google.com/gsa/answer/7528111?hl=en

Granville, Rich. n,d. About Yippy, Inc. (Accessed on 2 July 2019). http://www.yippyinc.com/company

Kogler, Ulrike. 2018. Mindbreeze Positioned in the Leaders Quadrant of the Gartner's 2018 Magic Quadrant for Insight Engines. (Accessed on 2 July 2019). https://www.marketwatch.com/press-release/mindbreeze-positioned-in-the-leaders-quadrantof-the-gartners-2018-magic-quadrant-for-insight-engines-2018-07-13

Kogler, Ulrike. 2018. KMWorld Ranks Mindbreeze Among the "100 Companies That Matter in Knowledge Management 2018." (Accessed on 2 July 2019). https://www.businesswire.com/news/home/20180308005681/en/KMWorld-RanksMindbreeze-\%E2\%80\%9C100-Companies-Matter-Knowledge 


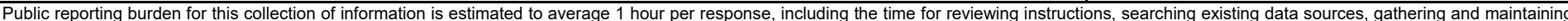

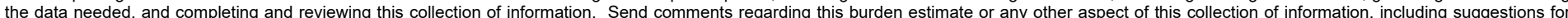

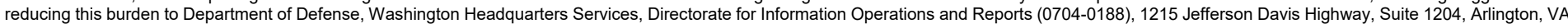

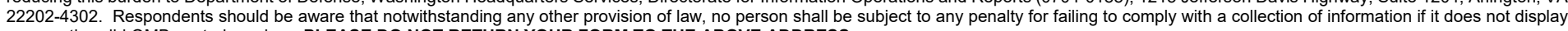
a currently valid OMB control number. PLEASE DO NOT RETURN YOUR FORM TO THE ABOVE ADDRESS.

1. REPORT DATE (DD-MM-YYYY) $\quad$ 2. REPORT TYPE $\quad$ 3. DATES COVERED (FrOm - To) June 2019

\section{TITLE AND SUBTITLE} SR

Google Search Appliance End of Life and Replacement Recommendations 5a. CONTRACT NUMBER

5b. GRANT NUMBER

5c. PROGRAM ELEMENT NUMBER

\section{AUTHOR(S)}

5d. PROJECT NUMBER

Byron M. Garton, Jonathan S. Broderick, and Brandon K. Randle

5e. TASK NUMBER

5f. WORK UNIT NUMBER

\section{PERFORMING ORGANIZATION NAME(S) AND ADDRESS(ES)}

Information Technology Laboratory

U.S. Army Engineer Research and Development Center

3909 Halls Ferry Road

Vicksburg, MS 39180

8. PERFORMING ORGANIZATION REPORT NUMBER

ERDC/ITL SR-19-2

9. SPONSORING / MONITORING AGENCY NAME(S) AND ADDRESS(ES)

10. SPONSOR/MONITOR'S ACRONYM(S)

Headquarters, U.S. Army Corps of Engineers

Washington, DC 20314-1000

11. SPONSOR/MONITOR'S REPORT NUMBER(S)

\section{DISTRIBUTION / AVAILABILITY STATEMENT}

Approved for public release; distribution is unlimited.

\section{SUPPLEMENTARY NOTES}

Office of Research and Technology Transfer (ORTT) utilizing 219 CDR funding for "ERDC Technology Transfer and Infusion/Knowledge Management."

\section{ABSTRACT}

The Engineering Research and Development Center (ERDC) Knowledge Management relies on a search technology provided by Google. Known as the Google Search Appliance (GSA), it indexes and searches ERDC's accumulation of knowledge stored on various web connected systems. The GSA provides a familiar and simple to use interface to facilitate quick location and retrieval of ERDC knowledge stored on these systems that are located on ERDC's internal and extra-net websites. In 2016, Google announced the discontinuation of the GSA product at the end of March 2019.

This document details the investigation into potential GSA replacement options and the recommended actions to be taken to minimize the impact of the March 2019 sunset. Emphasis is placed on equivalent or enhanced feature sets, ease of installation and migration, and the costs associated with installation, migration, and maintenance.

\begin{tabular}{|ll}
\hline 15. SUBJECT TERMS & Knowledge management \\
& Search engines--Evaluation
\end{tabular}

16. SECURITY CLASSIFICATION OF:

\section{a. REPORT}

Unclassified

b. ABSTRACT
Unclassified

\section{c. THIS PAGE}

Unclassified 17. LIMITATION
OF ABSTRACT 18. NUMBER
OF PAGES

25 19a. NAME OF RESPONSIBLE PERSON

19b. TELEPHONE NUMBER (include area code) 